\title{
Ser Bramtmentein.
}

\author{
- \\ E $\mathfrak{x} \mathfrak{d} \mathfrak{h} \mathfrak{\mathfrak { u }} \mathfrak{n} \mathfrak{g}$ \\ von \\ Hleranber Bronifowst.
}

Erfer Theil.

$\mathfrak{B}$ e c l i n,

im Berlage bei 3. 2 B. Boite.

1828. 

Der Grimmentein.

Erfer Theil. 
